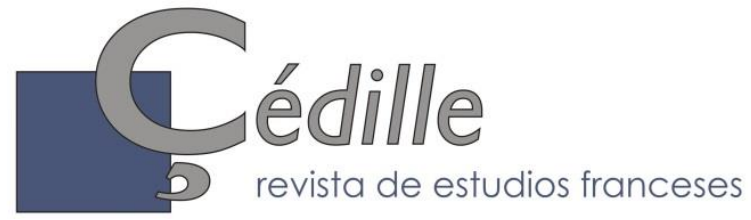

ISSN: 1699-4949

$n^{0} 18$ (otoño de 2020)

Monografías 11

Epistemocrítica: análisis literario y saber científico Amelia Gamoneda Lanza \& Francisco González Fernández, editores científicos

\title{
La estética cuántica: Juan Larrea, Niels Bohr y el tercero incluido
}

\author{
Candelas GaLA \\ Wake Forest University \\ galacs@wfu.edu \\ ORCID: 0000-0003-0549-0654
}

\section{Resumen}

El presente ensayo explora notables coincidencias en la poética de Juan Larrea con algunos puntos centrales de la física cuántica, a saber, la correlación entre su búsqueda en la interioridad y las investigaciones sobre el átomo en las primeras décadas del siglo XX, entre el abandono de la subjetividad monolítica en favor de un Espíritu universal y colectivo y el observador en la física moderna «enredado» en la trama cósmica, objeto de su observación y, en particular, el papel del idioma francés en tratar el conflicto con los binarismos occidentales y su posible resolución en la complementariedad de Bohr, paralelo de la teoría del tercero secretamente incluido de Basarab Nicolescu.

Palabras clave: Principio de la complementariedad, Estructura del átomo, Enredos cuánticos, Dualismos, Transdisciplinariedad.

\section{Résumé}

Cet essai explore les coïncidences remarquables dans la poétique de Juan Larrea avec certains points centraux de la physique quantique, tels que la corrélation entre la recherche dans son être intérieur et les recherches sur l'atome menées au cours des premières décennies du $\mathrm{XX}^{\mathrm{e}}$ siècle, entre la subjectivité monolithique en faveur de l'Esprit universel et collectif et de l'observateur «enchevêtré » dans la toile cosmique, objet de son observation, en physique moderne et, en particulier, le rôle de la langue française dans le traitement du conflit avec les dualismes occidentaux et leur résolution possible dans le principe de complémentarité de Bohr, parallèle à la théorie du tiers caché de Basarab Nicolescu.

Mots clé : Príncipe de complémentarité, La structure de l'atome, Enchevêments quantiques, Dualismes, Transdisciplinarité.

\begin{abstract}
This essay explores notable coincidences in Juan Larrea's poetics with some central points in quantum physics, such as, the correlation between the search in his inner self and the investigations on the atom taking place during the first decades of the twentiethcentury, between leaving aside the monolithic subjectivity in favor of a universal and
\end{abstract}

*Artículo recibido el 25/02/2020, aceptado el 25/10/2020. 
collective Spirit and the «entangled» observer in the cosmic web, object of his/her observation, in modern physics, and, particularly, the role of the French language in dealing with the conflict with Western dualisms and their possible resolution in Bohr's principle of complementarity, a parallel of Basarab Nicolescu's theory of the hidden third.

Keywords: Complementarity principle, The Atom Structure, Quantum Entanglements, Dualisms, Transdisciplinarity.

Juan Larrea (1895-1980), poeta y ensayista comúnmente afiliado con la llamada generación poética española de 1927, y Niels Bohr (1885-1962), físico ganador del premio Nobel de 1922 por su trabajo en la física cuántica y en la estructura del átomo, ni se conocieron en vida ni se mencionan el uno al otro en sus escritos. Pero lo más fundamental de la producción de ambos tiene lugar dentro del mismo marco histórico de comienzos del siglo XX, y los comentarios de Larrea sobre los experimentos en física, por un lado, y la importancia del lenguaje en Niels Bohr, por otro, reflejan un interés en ambos por el área considerada tradicionalmente como opuesta a la de su trabajo.

El objetivo del presente ensayo es explorar las notables coincidencias que la poética de Larrea presenta con algunos de los puntos centrales de la física cuántica, a saber, la correlación, que el mismo Larrea observa en su diario intelectual Orbe (iniciado hacia 1932), entre su búsqueda en la interioridad más profunda y las investigaciones sobre el átomo que Ernest Rutherford, Niels Bohr y otros físicos desarrollaron en las primeras décadas del siglo XX, entre su abandono de la subjetividad monolítica en favor de un Espíritu universal y colectivo y el sujeto observador en la física moderna como elemento «enredado» en la trama cósmica, objeto de su observación y, en particular, entre el conflicto con las dualidades y binarismos de la cultura occidental que confrontan a Larrea en su búsqueda, y su posible resolución en el principio de complementariedad de Niels Bohr, paralelo a un nivel ternario o tercero oculto, eco de la teoría del tercero secretamente incluido de Basarab Nicolescu ${ }^{1}$.

En la elaboración, a menudo confusa e imprecisa, que Larrea lleva a cabo en Orbe hay reverberaciones de los temas que por las mismas fechas se estaban planteando físicos y pensadores. Una nota común en todos ellos es la necesidad de confrontar las polarizaciones que habían definido la cultura occidental y la física clásica porque fijaban las deliberaciones en un callejón sin salida. En vez de se-

\footnotetext{
${ }^{1}$ Larrea mantiene una lucha interna que concuerda con la «(conciencia infeliz», término hegeliano que Jean Wahl en 1933 aplicó a Kierkegaard. Según Hegel, una «conciencia infeliz» es «the consciousness of self as a dual-natured, merely contradictory being», para la cual ambos términos se consideran tanto necesarios como contradictorios. La infelicidad procede de no poder deshacerse de una u otra de esas concepciones opuestas. Larrea busca un cierto control sobre esos polos opuestos « within this changing, finite world», pero su conciencia no logra aprehenderse a sí misma «as the self-same, to which both of the predicates 'infinite' and 'finite' are applicable». La imposibilidad tiene su lógica ya que los términos en cuestión son contradictorios y sujetos a un planteamiento de «either/or» (cit. en Hannay, 1982: 22, 27, 30, 28).
} 
guir considerando la cuestión en términos de polos irreconciliables, de «esto o esto», se busca una manera de complementarlos en un planteamiento de «esto y esto». No se trata tanto de cambiar la naturaleza de la realidad física, ya que la realidad sigue siendo lo que siempre ha sido, por eso y como reconocen físicos, teóricos y artistas, lo que hay que cambiar es el conocimiento. Parece haber un común acuerdo en poner a prueba las certezas tradicionales ya que los nuevos planteamientos en torno al conocimiento no son ni certeros ni completos; tampoco son fijos e inamovibles. Sorprendente es que esa misma incertidumbre resulte ser la fuente de nuevas vías de creación.

Las correlaciones en la manera de acercarse al conocimiento en figuras y áreas del saber muy distantes reflejan la transdisciplinariedad que intelectuales, artistas y científicos cultivaron a comienzos del siglo $\mathrm{XX}^{2}$. Reflejan, además, una tendencia a distanciarse de un conocimiento enfocado en la trascendencia en favor de la experiencia humana, de la inmanencia en la materia y de la vida. Varios estudios se han ocupado de conectar la física cuántica con las filosofías orientales y con la psicología. El mismo Wolfgang Pauli mantuvo una correspondencia destacable con Carl Jung sobre la sincronicidad entre eventos físicos y psicológicos. Pauli compartía el sueño del alquimista de fundir lo psíquico con lo físico en una unidad. Creía que era la responsabilidad del Occidente el aproximar Occidente y Oriente, es decir, lo racional/crítico con lo místico/irracional, con el fin de superar los contrastes y llegar a una síntesis en la que se fundieran el entendimiento racional y la experiencia mística de la unidad (Pauli, 1994: 24, 139,148) ${ }^{3}$. Un objetivo semejante se encuentra en los escritos de Larrea donde se articula como la disolución del yo en un Universo abarcador. Larrea señala un «paralelismo entre lo cósmico y lo psíquico», coincidiendo con el sueño de Pauli (1990: 163) de compaginar lo físico/analítico con lo psíquico/interior. A su vez, los poetas de su generación se interesaron por las ciencias, como reflejan sus escritos y declaraciones, y varios de ellos cultivaron las artes plásticas y la música.

Una diferencia clave en la cuántica con respecto a la física clásica tiene que ver con el observador. Frente al distanciamiento del sujeto respecto al objeto de observación, en la cuántica se da una total implicación de ambos polos hasta tal punto que el sujeto sufre una transformación. Pauli (1994: 22) propone que se trata de un Wandlung y en las reflexiones de Larrea sobre la correlación entre los fenómenos psíquicos y físicos correspondería a lo que él describe como una transfiguración o metamorfosis. Pauli, además, propuso la posibilidad de considerar los

\footnotetext{
${ }^{2}$ Para un estudio de las relaciones entre la poesía, el arte y la física en la generación poética española de 1927, véase el libro Sinergias de Gala incluido en la bibliografía.

${ }^{3}$ Las dos áreas quieren superar el determinismo estrecho de la causalidad y hallar una manera más general de conectar con la naturaleza, objetivo al que también apunta la cuestión psíquico-física. Fue William James quien en 1902 estableció la conexión entre el campo físico y el psíquico. Para Jung, no hay claras demarcaciones entre el consciente y el inconsciente pues uno empieza donde el otro termina, y para Pauli el único punto de vista aceptable es el que reconoce ambos lados de la realidad, el cuantitativo y el cualitativo, el físico y el psíquico, como polos compatibles (apud Pauli, 1994: 151,153, 259).
} 
instrumentos de medición en los experimentos físicos como extensiones del observador y sus órganos sensoriales, y constató que la conciencia es donde tiene lugar la síntesis del pensamiento analítico/racional y místico/irracional (Pauli, 1994: 153). Por su parte, Bohr (1958: 11) reconoció la analogía existente entre la interacción de objeto e instrumento de medición y el análisis psicológico donde el contenido mental es alterado cuando la atención se enfoca en algún rasgo de aquel.

Pauli (1994: 41, 42) reconoce la división que el concepto de conciencia exige establecer entre el sujeto y el objeto, pero observó también que cuando algo emerge en la conciencia el inconsciente sufre una interferencia que afecta la objetividad de la observación. Aunque en el mundo hay los dos polos del máximo misticismo y el máximo positivismo, Pauli constata que se compensan entre sí, haciendo posible el equilibrio. Esos polos son los que detentan la realidad vital por eso, según Larrea, el término dualidad «es el llamado a desaparecer mas no sin que antes, por el juego normal de las circunstancias, se agarre desesperadamente a la letra de las cosas». [...] La Conciencia del nuevo mundo «no consiente la idea de persona... Lo que parecía realidad subjetiva se convierte en realidad objetiva» (Larrea, 1990: 21; Cordero de Ciria \& Díaz de Guereñu, 1986: 328). Larrea vislumbra la realidad como una totalidad donde quedan englobados los dualismos.

En la búsqueda de conocimiento de sí mismo y del mundo, Larrea encontró relaciones analógicas con los experimentos que se estaban llevando a cabo con el átomo. Es más, Larrea reconoció la necesidad de recurrir a la ciencia para superar la ausencia de autenticidad y mediocridad creativa a nivel nacional e internacional, «y no solo restringido a la heredad literaria». Los culpables, según el poeta, eran la política y la sociología, por lo que afirma que:

[...] sólo una decidida maniobra orientada hacia el claro conocimiento científico puede salvar a nuestra época del mismo abismo que sumió las promesas que consigo traían los albores del renacimiento; maniobra de dar la espalda de una vez y para siempre al abusivo espíritu filosófico o metafísico si queréis, tan estéril como la experiencia de siglos nos enseña.

Hay que rechazar el «cotidianismo insípido», dice el poeta, la indumentaria espiritual con que durante siglos la filosofía se ha encargado de encubrir nuestra desnudez, añadiendo que: «Hay que sustituir el sistema apriorístico por la fecunda hipótesis de trabajo y la conformidad muelle con el dinamismo optimista» (Larrea, 1989b: 353).

\section{La desintegración: atómica, psíquica y poética}

En la entrada del 6 de marzo de 1932 en su diario intelectual Orbe (1926, publicado en 1932), Larrea dice estar leyendo un artículo en la revista francesa $L u$ que trata de la desintegración atómica y del descubrimiento del neutrón [sic]. Por fechas parecidas a las de esos experimentos Larrea confrontaba la desintegración 
en su interioridad, debatiéndose entre tendencias opuestas. Orbe da buena prueba de esta lucha interna, pero también «Presupuesto vital» y su libro de poemas Versión celeste (publicado entre 1969 y 1970 pero con poemas del período de 1919 a 1932). Esa aparente relación entre el plano físico y el psíquico, es decir, entre los experimentos con el átomo y la indagación subjetiva, le fueron revelando a Larrea que el conocimiento que se había formado de sí mismo, de su constitución interna, mostraba una rara correspondencia con el de la constitución del neutrón, especie de partícula eléctrica formada por una combinación de una unidad de electricidad positiva y de una unidad de electricidad negativa. Como pudo leer, el neutrón y el electrón no se contrarían y su presencia no produce trastornos en la constitución de la materia, mostrando una complementariedad que Larrea (1990:128) deseaba encontrar para sí mismo entre sus tendencias opuestas ${ }^{4}$. Evidentemente, esa coincidencia presentaba «un punto esencial de contacto con el de la teoría atómica»». Incluso había una equivalencia en la adquisición de ese conocimiento: «La desintegración atómica y lo que yo he llamado disgregación psíquica, mirando exclusivamente lo que dentro de mí pasaba, parecen ser semejantes». Si en la zona más interna del átomo se da la atracción que el núcleo ejerce sobre los electrones individuales por encima de su repulsión mutua, Larrea reconoce el imperativo de hallar una complementariedad entre las direcciones contrarias que lo dividen internamente (Larrea, 1990:129) .

Larrea incluye en su diario una representación gráfica del poema que tiene una curiosa semejanza con la que hace Bohr del átomo como un sistema planetario con un núcleo atómico en el centro y electrones girando alrededor del núcleo (Heisenberg, 1969: 39-40). En Larrea se trata de una circunferencia cuyo centro, que se correspondería con el núcleo del átomo, sirve de eje para las relaciones que se establecen con los elementos fuera del núcleo. A la izquierda, donde los lados de la circunferencia se abren para establecer contacto con el exterior, la gráfica sitúa los puntos $\mathrm{B}$ y $\mathrm{C}$, mientras que a la derecha aparece $\mathrm{A}$, que representa nuestra situación. AB es la trayectoria de nuestra ansiedad o deseo y AC la de nuestra profundidad volitiva. Se marcan, así, las trayectorias hacia la exterioridad y la interioridad con el núcleo como eje. El núcleo no permanece estático pues la apertura en la circunferencia permite la evasión, mostrando que el centro no se man-

\footnotetext{
${ }^{4}$ Aunque confiesa no saber la fecha exacta del descubrimiento del neutrón ni el de las otras experiencias de desintegración atómica de Cockroff-Walton, tampoco sabe la fecha cuando las teorías sobre su subjetividad se concretizan, lo que no le impide reconocer las coincidencias en las dos áreas en la búsqueda del conocimiento. Esta semejanza fue para Larrea muy significativa pues permitía sacar consecuencias lógicas que conducirían a descubrir las leyes por las que se rige la vida. Larrea comenzó su diario Orbe en 1926, la misma fecha de su «Presupuesto vital», y los pomas de Versión celeste proceden de parecidas fechas. Por entonces se estaban publicando en periódicos y revistas los experimentos físicos de que habla, como en $\mathrm{Lu}$, la publicación francesa donde Larrea leyó sobre el átomo.

${ }^{5} \mathrm{Y}$ añade que la desintegración atómica se logra «por la continuidad de un proceso voluntario y reflexivo, a lo que se llega a través de experiencias innumerables provocadas. Pero la desintegración psíquica es automática, espontánea, natural, ajena a toda participación consciente de la voluntad, puesto que la voluntad está llamada a padecer en la experiencia» (Larrea, 1990: 129).
} 
tiene [«the center does not hold»] y que, por tanto, nuestras trayectorias apuntan a metas en constante movimiento (Cordero de Ciria \& Díaz de Guereñu, 1986: 116$17)$.

El trabajo de desintegración atómica por Rutherford, junto con John Cockcroft, su mayor colaborador y Ernest Walton, reconocido con el Premio Nobel de 1951, interesó a Larrea especialmente por el aspecto de «desintegración» de un átomo considerado hasta entonces como el último reducto de la materia. En su caso personal, se trataría de desintegrar las creencias tradicionales constriñendo su libertad personal y artística, y como poeta, de someter el lenguaje a un proceso semejante de desintegración de sus estructuras convencionales, pulverizando la referencialidad de las palabras; de ahí se explica la complejidad que sus poemas presentan para el lector (Nieto, 1989: 44). Había que lograr que el sentido dejara de responder al principio de la causalidad y de un sujeto individualizado para emerger a partir de términos en relación con otros términos vecinos, de lo que resulta, en los poemas, «una fenomenal interacción de energías lingüísticas condensadas». «Imagen activa» es el nombre dado por Larrea a este fenómeno donde lo relacional de los elementos evoca los enredos cuánticos en la trama cósmica, y la ausencia de objetos individuales y discretos, pues su sentido solo se logra en relación con los otros en su entorno. Los poemas articulan un mundo caleidoscópico que requiere arriesgarse en los azares del lenguaje [«staking one's life on the chances of language»], pues para Larrea el poeta tenía que apostarlo todo al lenguaje si quería lograr la metamorfosis personal que solo el instrumento de la poesía podía proporcionar. Había que deshacerse de las viejas creencias y dejar que las imágenes se sucedieran a modo de fluido radioactivo donde «each thing is the other». El texto de Larrea es un tipo de combustión espontánea, según indica Bary (1987: X, XI, XII), haciendo que el lenguaje se encuentre en un estado a punto de hervir.

En «Carta abierta a Jacques Lipchitz»), Larrea le hace al arte contemporáneo responsable de descubrir un nuevo lenguaje y articular su propia manera de proyectarse hacia lo esencial. Para ello hay que llevar a cabo un verdadero trabajo de desintegración, hay que:

[...] desconcertar los componentes [...] desmontar las formas, darles vueltas, triturarlas entre los dientes de la geometría, a fin de forzarlas a rendir sus secretos íntimos y a revelar el modo cómo pueden conectarse libremente unos caracteres con otros en procura de una corriente de luz más intrínseca y recatada, verdaderamente esencial. A la manera como la física está explorando las interioridades atómicas, las artes literarias y plásticas han descompuesto las especies estéticas para imponer a sus materiales toda suerte de nuevas combinaciones y posturas (Larrea, 1984: 172).

La pulverización del lenguaje se verá regida por la geometría y sus formas y por la física en su exploración del átomo. Se trata de un proyecto basado en la convicción de que existe una trama cósmica donde todos los elementos se hallan 
entrelazados, impidiendo extraer el objeto de la descripción de la descripción misma, y desbancando la creencia de un sistema constituido por términos autónomos conectados por relaciones causales. El hablante es uno de esos elementos atrapados en la trama, o «cosmic web», fundido con el objeto de su observación (Hayles, 1984: 21). Bohr habló del drama de la existencia en la que somos actores y espectadores al mismo tiempo (1963: 15). Igualmente, Larrea llega a constatar que el sujeto debe ser desbancado de su puesto de preeminencia ya que es parte del mundo objeto de su observación.

Mientras que Larrea «pulveriza» el lenguaje en asociaciones impredecibles, Bohr nos recuerda que estamos «colgados del lenguaje», por lo que tenemos la necesidad de comunicar los fenómenos cuánticos mediante el «lenguaje común» y así mantener la objetividad y evitar la ambigüedad. Lo paradójico de este requisito es que los fenómenos cuánticos se encuentran más allá de la experiencia humana (Honner, 1987: 86) y, por tanto, del lenguaje común. La paradoja se resuelve cuando se considera que Bohr no busca un lenguaje que sea réplica del mundo observado, sino que comunique planos de realidad que no son accesibles directamente y que muchos de ellos son parte de la consciencia. En este sentido, para Larrea y Bohr no cuenta tanto que las palabras reflejen una realidad «real», sino que reflejen nuestro conocimiento de ella. Según Bohr, es inevitable el intercambio entre concepto y experiencia, aunque sea contradictorio por mezclar la subjetividad del observador con la objetividad en la observación, pero debe considerarse complementariamente, si se quiere acceder a un conocimiento más completo. De ahí su aprecio por la poesía, como bien señala Honner, basado en creer tanto en el poder metafórico de las palabras como en su poder referencial, pues las palabras no solo se refieren a realidades obvias, sino que también invocan realidades más profundas y elusivas (Honner, 1987: 223) ${ }^{6}$.

El foco de Larrea es la polaridad entre la vida y el conocimiento pues, ¿cómo entender los procesos vitales siendo parte intrínseca de ellos? La física cuántica estaba confrontando dilemas semejantes en la dualidad de partícula y onda, posición y momentum. El principio de incertidumbre de Heisenberg había identificado la imposibilidad en determinar simultáneamente la posición y el momentum, apuntando a lo incierto e incompleto del conocimiento. Bohr es quien con su principio de complementariedad ofrece una salida al conflicto.

\section{Principio de la complementariedad y el tercero incluido}

Larrea describe las notas o entradas en Orbe como nacidas de su vida, constituyéndose a modo de un poema «aparentemente dislocado«, es decir, sin un orden causal y lógico. Y se pregunta sobre el «terrible caleidoscopio» de la vida donde no es posible hallar un punto al que asirse (1990: 177). Como ejemplo ofrece el nombre de Adán, el supuesto primer padre, al que al darle la vuelta resul-

\footnotetext{
${ }^{6}$ «We are suspended in language in such a way that we cannot say what is up and what is down. The word "reality" is also a word, a word which we must learn to use correctly» (apud Petersen, 1985:302).
} 
ta en Nada. En la dualidad entre vida y conocimiento, Larrea presiente que será la vida la que desarrollará los medios de compaginar los opuestos, como ya se hace evidente en la precisión hallada en la célula, el átomo, los electrones. La vida, según Larrea (1990: 160), «parece tender a crearse en cada momento, a producirse de modo que un nuevo conocimiento sea añadido a cada instante a los conocimientos anteriores, modificándolos y vivificándolos de nuevo». Coincide así con Bohr pues, ya se trate del experimento cuántico, ya sea la vida, para poeta y físico se está trabajando con fenómenos totales donde las opciones permanecen abiertas, pero, al ser tomadas, fijan los rasgos del evento hasta que otro nuevo ocurra. Ambos entienden, entonces, que hay que hablar de una totalidad cuántica o «quantum wholeness» (Barad, 2007:196) o inseparabilidad entre sujeto y objeto, lo consciente y lo inconsciente. La insistencia en el fenómeno como totalidad se identifica en Bohr desde 1937, entendiendo por tal que cada fenómeno atómico es una unidad irreducible epistemológicamente (MacKinnon, 1985:119). David Bohm (1985:157) explica esa totalidad con el ejemplo de un «pattern» o «patrón» en una alfombra donde flores y demás rasgos «are disjoint objects of interaction». Igualmente, en una situación cuántica, el objeto observado, el instrumento de observación, las condiciones para el experimento y los resultados del experimento son aspectos de un único «pattern» que se destacan gracias al modo de articularlos en el discurso o lenguaje. Como no estamos ni distanciados del mundo ni somos superiores a él, sino parte de su constante reconfiguración, el conocimiento resulta ser una práctica de enredo o involucración física (Barad, 2007: 341, 342).

Bohr articula dicha involucración en su principio de complementariedad. El término «complementariedad», usado por primera vez por el físico en una conferencia en Como, Italia, en septiembre 1927 (Jones, 1985: 320), implica que en una situación donde los elementos aparecen contradictorios es posible llegar a un entendimiento más completo al considerar la situación desde dos ángulos distintos (ver Kothari, 1985: 325). Aunque se excluyen mutuamente, se complementan y es solo en su yuxtaposición que se puede lograr el conocimiento más completo del fenómeno (Heisenberg, 1985: 170). Contraria sunt complementa es una expresión inscrita en el escudo de armas de Bohr, diseñado en 1947 cuando se le concedió la orden danesa del Elefante, honor normalmente reservado a miembros de familias reales y a presidentes de estados extranjeros. Dicho escudo fue colgado al lado del escudo de armas del rey en la iglesia del castillo Frederiksborg en Hillerod. En él, y además de la inscripción, Bohr eligió el símbolo chino del yin-yang por representar dos elementos de la naturaleza que son opuestos pero inseparables (Wheeler, 1985:223-224), y, en la misma línea, la idea central del instituto que Bohr dirigió fue que no hay progreso sin paradoja.

Si el principio de complementariedad de Bohr sitúa el conocimiento en la yuxtaposición de dos modos distintos de interpretación, Larrea (1990: 161) lo sitúa en un nivel ternario o tercer elemento que nace precisamente de los elementos polarizados: «entre sí nace de la mutua presencia de ambos un tercer elemento, un conocimiento que viene a modificar la creación, a polarizar de nuevo las fuerzas sintéticas creando una multiplicidad ilimitada de repercusiones cuyos resulta- 
dos dualizados se vuelven a encontrar frente a frente». Ese nivel ternario tiene agencia activa en la creación, la modifica, pues reactiva la polarización sin disolverla en síntesis; de resultas, produce opciones múltiples, es decir, da pie a la creatividad mediante el mantenimiento de las polarizaciones. Y así sucede en ambos, Bohr y Larrea, donde se trata de mantener las polaridades, no de fundirlas en una síntesis. Para Larrea un ejemplo se da cuando una idea o noción emerge en la mente y ahí queda hasta que un hecho exterior la estimule «como en la superficie de un espejo polarizado en forma contraria». La imagen especular reproduce el original sin fundirlo, manteniendo la diferencia en la semejanza, de igual modo que la diferencia en Bohr llega a una complementariedad al aplicar distintos modos de interpretación. En el ejemplo de Larrea (1990: 155) lo vital o experiencial se yuxtapone a lo mental, como si se tratara de una «amalgama de lo que es y lo que no es», siendo así «la vida misma, resumen del todo de dos maneras diferentes que al unirse se imaginan, presentando cada cual, como en un espejo, la imagen equivalente de lo que está en la otra». El espejo de Larrea, como el principio de Bohr, funde dos elementos contrarios pero complementarios. Lo que es evidente en ambos planteamientos es que las creencias absolutas y fijas no tienen cabida, incluyendo la de una objetividad absoluta que, como señala Larrea (1990: 162), carece de «potencia analizadora».

La noción de tercer elemento es lo que Basarab Nicolescu (2013: 33-34) describe como «tercero secretamente incluido» donde se produce «la interacción ternaria del conocimiento». Ese tercer término es a la vez A y no-A pues permite una «reciprocidad de opuestos» (Francisc-Norbert et al., 2012: 131), logrando unificar los contrarios sin alcanzar una síntesis o estado de no-contradicción, pero posibilitando que el conocimiento evolucione. Exige que «un par de condiciones contradictorias $[. .$.$] deben y pueden atribuirse» en alternativa a un tercer término$ T que es a la vez A y no-A y que ejemplifica una lógica de la complejidad. Para Nicolescu se trata de un elemento oculto y transcultural que funciona como catalizador en el génesis de la realidad. Este recurso mediador es esencial ya que es en esos espacios intermedios donde tiene lugar la creatividad y la imaginación (Francisc-Norbert et al., 2012: 129, 132). Aunque Larrea no menciona a Nicolescu, se trata en ambos de llegar a un nuevo nivel de conocimiento con el que afrontar las «(sorpresas») que las investigaciones en la nueva física, en el arte, la literatura y la psicología estaban revelando.

En «Diente por diente» Larrea ofrece una elaboración aún más sorprendente sobre la coincidencia de su pensamiento con Bohr y Nicolescu. El poeta anuncia que «Por entre las junturas de los hemisferios un espacio aventurero empieza a brotar. A su luz todo lo evidente se desploma y salda su sentido. Lo que ha sido ya no es, las grandes creencias se despeñan como policías suicidados» (Larrea, 1989a: 152). El poeta proclama el «advenimiento» de un espacio en la juntura que divide la esfera cósmica y, también, la esfera donde se han venido encapsulando los valores establecidos. Ese espacio divide la perfección de la esfera, atrevimiento que le merece el adjetivo de «aventurero» y subversivo, se diría, pues en su ámbito se produce el colapso de todo lo que se aceptó como evidente y palpable. 
Todos los credos admitidos se desmoronan, como si los policías mantenedores del orden convencional se suicidaran. Derrida lo denominaría el colapso de la estética $\mathrm{u}$ orden de la presencia o de la mismidad, dando paso a un estado curiosamente paradójico de que una situación pueda ser una cosa y otra al mismo tiempo. Y Larrea (1989a: 151-152) añade que:

Un confuso torbellino traslada al infinito el punto matemático donde nuestras vísceras se juntan. Ya no se sabe dónde está lo alto ni lo bajo, ni el dolor, ni siquiera el vértigo a que asirse. Ya no se sabe cuál de los dos labios es el superior y como tal obedecido, cuál debe ser comparado al alba, cuál al poniente.

Ese punto matemático, donde tiene lugar la cohesión, se sitúa a una distancia infinita, dejándonos en un estado de desintegración de nuestras vísceras y extremidades, con el sentido convencional de dirección y orden cronológico totalmente trastocados.

El tercer elemento, ese espacio aventurero donde puede alcanzarse la complementariedad de contrarios, fuente de la creatividad, es objeto de indagación en los poemas, en particular, pero también en anotaciones en Orbe y otros escritos («Presupuesto vital»y «Carta abierta a Lipchitz»). Para Miguel Nieto, editor de Versión celeste, se trata de desdoblar la subjetividad, eliminar el yo-tú para dar entrada a un tercero «donde descargar la tensión creada por el vértigo, el origen vacío de la inspiración y la carencia de realidad». El tercero, como«escisión de la primera persona en otro sujeto» supone una crítica irónica de la subjetividad y su supuesta autonomía (Nieto, 1989: 43-44, 46). Según Francisc-Norbert et al. (2012: 131), la presencia de un tercer término crea un intervalo donde hay espacio para perspectivas nuevas gracias a la imaginación y la creatividad. El tercero incluido permite una «reciprocidad de opuestos» lo que, en otros términos, venimos denominando la complementariedad. Según Larrea (1990: 163):

El presente tiene que estar de acuerdo con el pasado y con el futuro. [...] Y en nosotros hay algo esencial que no siendo es y que siendo no es. Hay un objeto y un sujeto. Y en esto hay una tal correlatividad que no pueden ser concebidos el uno sin el otro. El sujeto no puede concebir otro objeto que la vida humana y la vida humana como sujeto no puede concebir otro objeto que el hombre. Pero por encima de todo esto está un modo de ser último que ni es sujeto ni objeto particularmente, sino que tiene que ser los dos al mismo tiempo.

Y esa sensación existe en nosotros, aunque oculta bajo las apariencias (Larrea, 1990: 216).

El hablante en Versión celeste se define ocupando un espacio intersticial o tercero, en «transition entre la plume et l'ange» (Larrea, 1989a:110): la pluma, sinécdoque de la escritura en su realidad material y el ángel de la inspiración. Según Andrei Plesu, quien interpreta el mundo de los ángeles a partir de las teorías del tercero oculto de Nicolescu, el ángel transforma el límite que separa polos 
opuestos en algo flexible «within which the entities, although they interpenetrate, still remain indistinct» (Francisc-Norbert et al., 2012: 132). El ángel funciona entonces como un interfaz complementario, facilitando el diálogo entre sujeto y objeto, pero sin remplazarlos ni fundirlos en síntesis. Coincide así con el tercer oculto de Nicolescu en su función de «an accelerator which we will use to create perspectival spaces» (Francisc-Norbert et al., 2012: 140). El poeta con su instrumento, el lenguaje, es el catalizador entre lo material de la escritura y lo mental, polaridades que nunca se funden en una síntesis superior sino que, como sucede con la complementariedad y el tercero incluido, multiplican la creatividad en el mantenimiento de las polaridades. La acción de la lógica del medio incluido en los distintos niveles de la realidad induce una estructura abierta, pero godeliana, del conjunto de niveles de la realidad. Bohr y Larrea reconocen la riqueza que comporta el mantenimiento de polaridades complementarias, junto con el gran impacto que tiene en la teoría del conocimiento, porque implica la imposibilidad de una teoría cerrada sobre sí misma: el conocimiento es incompleto, pero siempre abierto.

La polarización y su impacto en el conocimiento en los poemas de Larrea presenta al hablante como «cazador furtivo», siempre al acecho de ese espacio intersticial frecuentemente designado como un «Tú» cuya naturaleza, como punto intermedio, altamente inestable, donde se produce el encuentro de los contrarios, es difícil de apresar. Ese espacio se hace más patente en la hora del crepúsculo, cuando el día y los ánimos decaen, ocasionando una encrucijada: «craque ici comme un chemin qui se fourche». Es el espacio que ocupa el hablante en «Chaise bonheur» (Larrea, 1989a:120): «Partiellement assis sur un filon d'âme», debido a lo precario de su posición, el hablante no se atreve a «bouger de peur que ciel et terre ne grincent les gonds de notre vie privée». La opción de uno u otro camino abierta en la encrucijada puede provocar efectos mayores en el edificio de la propia identidad, al exponerse a un equilibrio incierto. El poeta comprende que las avenidas son muchas (Larrea, 1989a: 132), pero todas ellas conducen a la «même étoile de mer battue / par où l'expérience écoule ses trésors prix coûtant». Todas las avenidas avanzan en el seguimiento de la misma estrella, cuyo idealismo orientador ha sido batido por la inestabilidad del mar, haciendo tambalear la experiencia.

Versión celeste refleja la dedicación de Larrea a la poesía que David Bary caracteriza como «entrar en poesía», al modo que un caballero lo haría en su orden, renunciando a su herencia cultural en sus aspectos más exteriores y superficiales para dedicarse a la búsqueda de una vida nueva y auténtica. Desde joven, y debido a distintas experiencias, Larrea desea salirse « «de los límites tradicionales de la conciencia dualista de Occidente». Su constante tema es ir más allá de un ambiente estrecho y asfixiante donde domina un pensar basado en dualismos carentes de imaginación (Bary, 1976: 22, 23, 31). Este deseo se añade a un rechazo 
del control exclusivo de la razón, y a entender que hay cosas que suceden que no tienen explicación lógica ${ }^{7}$.

\subsection{El idioma francés}

El papel del francés como idioma es fundamental en la exploración personal, poética, social y filosófica de Larrea (1989a: 93). En francés es como empezó a escribir y su obra, y su razón de ser, se encuentra en Francia: «Mi modo de ser está de acuerdo con el modo con que se produce la vida en Francia» (Larrea, 1989a: 138). Puede decirse que el idioma francés funciona a modo de tercero incluido en la poética de Larrea pues, como explica en su «Prólogo del autor», se sirve del francés por encontrar

[...] más dúctil y matizado aquel idioma, y, por lo mismo, especialmente idóneo para expresar en claves estéticas sus estados de conciencia esencial, desarticulados, turbios, difíciles, y sentidos en concordancia con las posibilidades que ofrecían algunas de las técnicas imaginativas descubiertas por la mejor audiencia internacional del momento (Larrea, 1989a: 61).

Version céleste fue escrito originalmente en francés y traducido después por varias personas, por lo que, como dice Miguel Nieto (1989: 11) en la introducción, parece una obra francesa en edición bilingüe. El libro parte de la división que Larrea admite haber experimentado entre su interioridad y el mundo externo y superficial (Nieto, 1989: 14). Larrea visitó París en 1923 para ver a Vicente Huidobro, al que había conocido en Madrid en 1921. Huidobro le presentó a Juan Gris, Jacques Lipchitz y Tristan Tzara. Ya por entonces Larrea, como Huidobro, estaba escribiendo en francés, pues había sido educado en una escuela dirigida por monjes franceses (Bary, 1987: VII). Se instaló en París en febrero de 1926 y allí residió hasta 1935. Su referencia al surrealismo, movimiento con el que la crítica suele asociar a Larrea, como un no saber la significación de lo que se dice, establece una clara división entre significante y significado además de esclarecer una clave de su propia poesía como «revelación» de un tipo de saber que no se articula según parámetros racionales. Se articularía, según lo dicho anteriormente, en ese tercer término donde la autonomía del sujeto se descoyunta para dar entrada a otras versiones de conocimiento. En «Presupuesto vital» (Larrea, 1989b: 353), Larrea se queja de la situación del español, pues desde hace siglos lo que de auténtico hay en el idioma se debe a la importación de elementos del exterior. Y

\footnotetext{
${ }^{7}$ El original del libro que Larrea dio a Vittorio Bodini, quien preparaba una antología de la poesía surrealista española, tenía cuatro partes: «Metal de voz» con 15 poemas en español, «Ailleurs», «Pure perte» (todos en francés excepto uno, «Espinas cuando nieva», escrito como homenaje a Fray Luis de León y por pedido de Diego, versión españolizada de «En costume de feuilles mortes») y «Version céleste», todo en francés (Nieto, 1989:40). Los títulos «Ailleurs» y «Pure perte» se encuentran en una frase de Rimbaud que Larrea encontró en 1929 en el libro de Rolland de Renéville, Rimbaud le voyant, que tanto le influyó : «Si'il tenta une dernière fois de leur faire entrevoir son âme, ce fût dans un besoin d'humilité et de rémission, qui s'exerça d'ailleurs en pure perte».
} 
afirma: «Así está nuestro idioma de rechinante e incurtido, así extraordinaria es la página donde las palabras no huelen a diccionario y sí a boca fresca, así nuestra sensibilidad circulante está de paquidermizada y nuestra historia literaria se reduce a una simple suposición de flores a porfía en el vacío». Larrea se «escapa»a París y escribe en francés no tanto para dar la espalda a mitos religiosos que, después de todo, recibió de su educación con padres Escolapios y con la orden francesa de los Sagrados Corazones (Bary, 1987: 29-30), sino para librarse de su interpretación y manipulación dentro de la burguesía española en Bilbao ( $c f$. Smith, 1995).

Según Paul Ilie (1970:330), la complejidad e irracionalidad de la poética de Larrea se debe a que al escribir quería articular el ardor interior que sentía, pero sin caer en el sentimentalismo o confesionalismo, de ahí que destruyera toda base racional. Con este seguro anti-racional contra la banalidad realista, Larrea se acerca a la escuela francesa, abandonando la lógica según lo prescrito por Reverdy y Breton en su primer manifiesto. Al establecer conexiones entre realidades contrarias, el poeta fabrica absurdidades que parecen involuntarias y debidas al azar y que, a su vez, evocan los principios de contrarios yuxtapuestos en la complementariedad cuántica. Si la dualidad de partícula y onda se define en la medición u observación, en la poesía es el poeta quien, como ya sugirió Pauli, ocupa el puesto de mediador, de un tercero incluido compaginando subjetividad y lenguaje, lo que resulta en una poesía semejante a una performance artística de gran complejidad, sin un sentido básico que sea más profundo que su forma externa. La ausencia de cohesión racional supone que los pensamientos y sentimientos nunca cristalizan en imágenes bien delineadas. Los poemas no presentan imágenes repetidas que permitan detectar pistas, por lo que no hay forma de apresar un significado. Son parte de un estado de ánimo imposible de dividir en segmentos individuales pues, como parte intrínseca de la trama cósmica, se hallan enroscados. Su valor estriba, entonces, en su poder acumulativo y colectivo y no en la fuerza de sus descripciones por separado. Reflejan lo que Ilie caracteriza como «subconscious awareness» (Ilie, 1970: 331, 336, 338).

Para Larrea el poema auténtico emergerá si el ego del poeta se sacrifica al libre juego de atracción y repulsión entre sensibilidad e inteligencia, es decir, si la preeminencia del sujeto deja paso al juego complementario de opuestos, sin buscar una síntesis unificadora y admitiendo la incompletitud en el conocimiento. Se trata para el poeta de una lucha dramática que crea movimiento, calor y vida. En cuanto al lenguaje, en 1932 Larrea declaró la adhesión del poeta a un entendimiento de su empresa como actividad de riesgo con el fin de alcanzar un nuevo estado ontológico, de auto-descubrimiento y de auto-transformación que, en última instancia, sería precursor de una transformación colectiva de la conciencia occidental.

Larrea nos insta a revolucionar con pasión «esa hereditaria monarquía filosófica» cuyo foco es la perfección pues es una «noción mortífera y estancadora». La perfección no existe, ni tampoco la verdad y la belleza. En vez, hay que creer «en la evolución progresiva» pues lo que cuenta en la obra artística es la 
emoción, es decir, «su imperfección, su movimiento»(Larrea, 1989a: 354). Por eso, y hablando del lenguaje, Larrea (1990: 49-50) ensalza el hecho de que ya no se detiene en el mero efecto fonético para entregarse a la imaginación. Y lo atribuye a la poesía moderna:

Justement toute la poésie moderne n'a fait que dépouiller le langage de sa propriété immédiate de soutenir une signification vulgaire. [...] Il n'y a pas de signification immédiate. Il $\mathrm{y}$ a une allusion en toute espèce de rapports imagés avec l'harmonie universelle. C'est l'imagination qui travaille débarrassée du poids mort de la vie quotidienne.

Cuando Larrea descarta la significación inmediata, está reiterando la incertidumbre e incompletitud del conocimiento que la física cuántica estaba revelando. No hay significación inmediata; hay una alusión llena de relaciones imaginativas con la armonía universal. Ensalzar la imaginación frente al peso muerto de la vida cotidiana, como hace Larrea, se corresponde con el reto que la cuántica presenta a los principios de causalidad, de tiempo y espacio, de separación de sujeto y objeto en la física clásica (Larrea, 1990: 276).

Version céleste es un título con distintas acepciones. Para Nieto parece derivar de la expresión «plano celeste», muy usada en Orbe y en el epistolario entre Larrea y Gerardo Diego, donde sirve «para designar el modo o lugar donde se afirma la vida del espíritu». Se trata, entonces, de un conocimiento asociado con la idea de la Afrodita Urania o Venus celestial, es decir, la espiritualización de Eros o Amor que es el amor intellectualis Dei. Además, el término «versión» se puede interpretar como «traducción» de la realidad al modo celeste de entenderla, o como «vuelta» o giro del cielo sobre sí mismo en un cambio de postura hacia el ser humano, enfocándose en el papel del poeta/observador; y, también, se aplica la etimología que adecúa «versión» a un libro de «versos»(Larrea, 1989a: 41). Estos distintos significados señalan un intercambio entre los planos celeste y terrestre, entre trascendencia e inmanencia, entre lo divino y lo humano, aspectos todos que sugieren un cuestionamiento de las jerarquías y perspectivas convencionales.

Deseoso de escapar o superar los dualismos, Larrea titula uno de los libros en Version céleste, «otro lugar» distinto al contexto europeo, específicamente el ambiente de Bilbao donde el poeta vivió, con su burguesía nutrida de creencias establecidas. La noción de «ailleurs» coincide con el deseo de lograr un nivel nuevo de vida y conocimiento que, como se viene analizando, Larrea investigaba «pulverizando» lugares comunes en el lenguaje. En Orbe ese «otro lugar» recibe el nombre de Espíritu universal con el que el poeta desea fundirse para sobrepasar la individualidad de un sujeto concebido como autónomo y distanciado de la realidad. Los poemas de Larrea se construyen sobre la base de un diálogo entre el yo del hablante y un tú también designado como Ella, con mayúscula, que bien puede ser ese nivel tercero que el poeta busca para la poesía, y también el amor y/o la vida misma.

Para llegar a ese «otro lugar», los poemas insisten en «desnudarse») de falsas convenciones y ritos sociales y llegar a un fondo de la interioridad donde 
superar las dualidades, apelando a ese tercer elemento o conocimiento que se comparte con el ser o espíritu universal. Ese proceso se describe con la imagen poética de «s'effeuiller les os» (Larrea, 1989a: 96), es decir, despojarse de cubiertas falsas para llegar a la médula. El poeta reconoce lo arriesgado, y atrayente a la vez, de su intento -el título del poema donde se encuentra la imagen y que abre la sección «Ailleurs» es «Attraction du risque»-, y constata que el «couler» que promete «entre les feuilles nées de vous avoir connue», es decir, moviéndose entre las hojas nuevas del libro y conocimiento que Ella le abre, supone «un printemps provisoire» carente de certezas (Larrea, 1989a: 108). Además, la búsqueda hacia «otro lugar» donde sea posible el logro de la complementariedad se revela constantemente evasiva.

Por eso dice que los logros son apenas «petits tas de nudité» o pequeñas revelaciones, pues llegar «jusqu'au jardin profond» (Larrea, 1989a: 122, 126), evocación del paraíso primordial y médula de lo esencial, «Instinct origine d'aube et d'auberge», ya está marcado por el dolor: el surtidor de su fuente primigenia es «l'épine haletante d'un jet d'eau» (Larrea, 1989a: 98, 126). La aventura hacia una esencial desnudez interior es un viaje plagado de lágrimas, ya que el conocimiento implica la pérdida de la inocencia que viene con la inscripción del signo y el exilio en soledad. Siguiendo el modelo de la pulverización del átomo, en busca de la materia prima que constituye el cosmos, el poeta, como el físico, se topa con una materia que se va descomponiendo en fragmentos cada vez más pequeños en un proceso de retroceso al infinito. El paraíso es «filant», en constante movimiento «vers la larme infinie». El mito del origen primigenio pierde solidez y acarrea el dolor pues implica la entrada del tiempo, «le tabernacle du temps [que] s'entoure de genoux de paupières» (Larrea, 1989a: 126). Como tabernáculo donde se guarda el pan sagrado o vellocino de oro como premio de la búsqueda, el tiempo exige que los buscadores se arrodillen ante él con los ojos bajos, reconociendo humildemente su realidad efímera. Con su representante en el reloj, el tiempo supone una corona de espinas («notre couronne [...] d'épines») cuyo círculo nos «corona» con nuestra mortalidad. También marca nuestras percepciones pues nuestros ojos están «adhérés au ciel par des nuances votives» (Larrea, 1989a: 118, 102). Estamos «adheridos» al tiempo y en su altar dejamos nuestra vida como ofrendas votivas.

Otro ejemplo de dualidad se da en las playas que «hésitent entre le ciel et leurs menus devoirs» (Larrea, 1989a: 122). La expansión de una playa, como la de la hoja en blanco, se sitúa entre el movimiento ascendente hacia el cielo o el plano ordinario dedicado a tareas diarias donde dar refugio a los veleros de la imaginación. Si la opción es la trascendencia, los veleros acabarán en naufragio «dépareillé» (Larrea, 1989a: 136) y las olas, por su parte, en vez de continuar su movimiento ondulatorio y creativo, buscarían agarrarse a lo que fuera «pour plaire au plus large des peupliers», es decir, comprometerían su energía creativa para « «agradar» sin riesgo. Ambas opciones no logran superar el dualismo. Los poemas ilustran las dificultades en lograr el nivel tercero de la complementariedad. 
En el poema «Folie de la danse» (Larrea, 1989a: 130), el hablante poético se sale de los confines del yo en la danza de la creatividad y del erotismo, que es en sí la danza de la vida. Sus manos representan el contacto «de chambre qui communique avec l'étable», uniendo elementos contrarios como son lo «doméstico» humano con lo animal. Sus ojos «se gercent à la surface d'une eau de table», otra referencia a esa domesticidad que en otro lugar considera «(mediocre» y asocia con la vida en el medio burgués donde creció, mientras que «Sur la table une fleur résume sa presence d'esprit». Ella, la poesía a la que aspira el hablante y que se identifica con ese espacio intersticial o nivel ternario donde reside la vida, devora a los que persisten en estar adormecidos ante la realidad, y en su avance, se va deshaciendo del peso de las estatuas o creencias convencionales: «Elle mange les victimes d'un dormeur solitaire / En marchant elle dégage une statue à chaque pas».

En esta «folie» de la danza de la creatividad intervienen todos los aspectos sensoriales y físicos de ese espacio ternario: olor, voz, manos, ojos, andar, apetito, hasta llegar en la estrofa final a la piel o envoltura que «n'est qu'une nouvelle forme d'obéissance», es decir, obediencia a fundirse porosamente en los enredos de la trama cósmica. Cuando eso ocurre, del alma del poeta se desprende una pelusa («duvet») como descarga sexual que sale «en tribus de neige ou d'os secoués par la danse» $\mathrm{y}$ «des petits tunnels de mes jambes visibles» (Larrea, 1989a: 130). Va dirigida hacia el ombligo del Tú, el triángulo donde los opuestos se complementarían, espacio aventurero generador de la creatividad que Larrea asocia con las tendencias de la nueva poesía francesa.

\subsection{La analogía y el tertium datur}

Esas «infinitas posibilidades» nos devuelven, de nuevo, a la riqueza de la creatividad en sus múltiples opciones que Larrea vislumbra en el nivel ternario. La exterioridad se inserta en la interioridad, lo cósmico en lo personal, y lo sobrenatural se ajusta a la medida humana. La analogía de Huidobro le sugirió a Larrea el puente entre la trascendencia y la inmanencia, lo personal y lo universal, lo celestial y lo mecánico, dando así cierre al predominio de dualidades irresolutas en la tradición cultural. Efectivamente, el poeta constata que el universo está a la medida humana, y al revés, pues el ser humano es parte del universo que observa y mide. A partir de esta analogía inicial, Larrea percibe la conexión de individuo / universo, de lo subjetivo con la exterioridad cósmica como polos de una misma realidad e insertos en su individualidad.

Lo que parece haber impresionado más a Larrea es que el verso de Huidobro desafía la estrategia característica de la analogía basada en comparar una situación desconocida con algo familiar, proporcionando seguridad (Hofstadter \& Sander, 2013:39). Pero ¿qué seguridad puede obtenerse de una luna que suena como un reloj? Aventurándose a imaginar, es posible que Bohr tuviera en mente ese rasgo de la analogía al insistir en el uso de un lenguaje común con el que comunicar nociones cuánticas nada familiares de una manera que proporcionara cierto grado de seguridad en un mundo pleno de incertidumbre. El filósofo Enzo 
Melandri, por su parte, señala la oposición que se da en la analogía contra el dualismo en la lógica occidental y atribuye a la analogía la capacidad de proporcionar el tertium datur que supone el no optar por ni A ni por B (cit. en Agamben, 2009: 19-20). La analogía no busca una síntesis entre esos contrarios, pues no hay síntesis posible entre la luna y el reloj; lo que busca es que sus identidades sustanciales se evaporen como si estuvieran en un campo electromagnético.

La analogía, compañera de la complementariedad y del tercero incluido, constituye un elemento destacable en la estética/poética cuántica de Larrea. El poeta entiende la analogía como un medio de conocimiento con la capacidad para unir lo igual con lo diferente en lo que Gamoneda (2015: 7) caracteriza como un «comunal trance» donde se vincula «la identidad y la alteridad, el yo y su doble, lo real y su espectro, certeza y conjetura, saber científico y sabiduría artística». Esas relaciones entre elementos tradicionalmente contrarios facilitan el logro de conocimiento pues, como ya señaló Henri Poincaré, «fuera de las relaciones, no hay realidad cognoscible» (apud González Fernández, 2015: 47). Agamben reconoce el valor de esta vocación relacional en la analogía como instrumento para minar esquemas de pensamiento bipolares (Cifre-Wibrow, 1984: 266).

$\mathrm{Al}$ analizar las analogías en los poemas de Larrea destaca el papel que juega la intuición pues, al revelar la gran diferencia que existe entre los polos relacionados, solo una captación intuitiva podría detectar las correspondencias (González Fernández, 2015: 73). Y en esto Cifre-Wibrow (1984: 265) percibe una trampa pues, al intuir una cierta u oculta correspondencia entre los dos polos, se nos invita a continuar indagando en la posibilidad de que haya otras semejanzas no visibles a primera vista pero que ayudarían a desentrañar un significado mayor. La analogía juega, además, un papel existencial muy notable pues altera la estabilidad que Larrea percibe como un estado sinónimo con la muerte. La existencia es una lucha en torno a esos polos opuestos que se deben armonizar, pero nunca fundir, eliminando sus particularidades. Y en esa batalla se dan espasmos, sorpresas, lo que, en el lenguaje del caos, se llama clinamen, que sirven de palanca para las estructuras disipativas que Larrea describe como la necesidad de «remover entrañas y moléculas». Por eso la existencia exige inmolarse «a la atracción y repulsión que entre sí experimentan inteligencia y sensibilidad» $\mathrm{y}$, como ya se ha indicado, hay que asirse «al espíritu científico para llegar a un imprescindible conocimiento». La inteligencia y la sensibilidad son «las dos coincidentes mitades del tórax artístico» (Larrea, 1989b: 350, 351, 352). La complementariedad en el tercero incluido se va probando como fuente no solo de conocimiento, sino de la misma vida.

Es el arte, según indica Wagensberg (apud Gamoneda, 2015: 119, 124), donde más claramente se evidencia el papel de la intuición y su capacidad de comunicar complejidades «no necesariamente inteligibles». Y quizá ahí radica la complejidad del lenguaje poético de Larrea que, basándose en la analogía, donde los polos opuestos se yuxtaponen mediante la intuición, se revela su semejanza con los enredos cuánticos y la dificultad en precisar los contornos de las cosas y determinar el significado. Además de la intuición, en la analogía cuenta en gran 
medida la percepción, que Larrea menciona al referirse a los párpados en varios poemas. El sujeto observador capta un entorno en movimiento constante en el que el sentido se mantiene incierto.

La complementariedad y la analogía conforman muchos de los planteamientos poéticos en Larrea. «En gardant les distances», título que alude a la convencional distancia entre sujeto y objeto, lenguaje y mundo, la analogía se establece entre los «astres sur leurs chevets» $\mathrm{y}$ «bateaux coupés en deux par une ligne idéale / à droite les horizons les beaux naufrages l'allure soucieuse / à gauche l'haleine en croix des lois physiques» (Larrea, 1989a: 26). Esos astros sobre las cabeceras aluden a un tipo de inspiración trascendente iluminando las cavilaciones mentales del sujeto observador en su intento de dilucidar enigmas. Larrea compara esa situación con barcos cortados por la mitad para ilustrar la división en el poeta, debatiéndose entre un conocimiento que apunta a un horizonte que acaba naufragando, y otro regido por leyes físicas que «crucifican» las verdades establecidas. La analogía, por tanto, yuxtapone la trascendencia y la inmanencia, las creencias tradicionales y la ciencia, denunciando los típicos binarismos de la cultura occidental.

La correlación entre opuestos en la complementariedad se expresa mediante enlaces como otro medio de establecer analogías. En «Liens» (Larrea, 1989a: 104), el hablante anhela esos lazos, fusiones y articulaciones «de soufflé et de poussière», o, en otras palabras, de aire o trascendencia y tierra o inmanencia. Toda esperanza de conocimiento se perdería de no lograr mantener los lazos entre esos opuestos, pues la realidad es un «collier» (Larrea, 1989a: 110) donde todo se encuentra engarzado, y no siempre en un orden claro y distintivo. Por eso queda claro que la meta no es disolver las polaridades en una síntesis, sino mantener los enlaces, aunque impidan lograr respuestas claras. Y es porque la realidad del universo se revela como una red o trama de elementos todos enredados en su urdimbre. Y aunque los enredos cuánticos no se mencionan directamente, las imágenes en los poemas apuntan a nociones parecidas.

\section{La complementariedad y la vida}

«¿A qué leyes poéticas, incluso idiomáticas, obedece la vida en sus resonancias? [...] ¿Qué terrible caleidoscopio es éste, en el que la imaginación se encuentra diluida? ¿En dónde queda el punto sólido a que asirse?», se pregunta Larrea (1990:177). El título de esta sección enuncia lo que puede ser la respuesta a sus preguntas.

El viaje de Larrea a Latinoamérica se puede entender como su intento de poner en práctica, en su propia vida, la complementariedad de opuestos que experimentó en el verso de Huidobro. Así, dijo que quería dejar en Europa «todas sus viejas fórmulas de civilización», desnudarse de todas esas creencias para bañarse «en el manantial de la inocencia del mundo» y de ese modo empezar su aventura. Con nuevos ojos, todo lo que hallaba en su entorno le parecía asombroso porque en ello veía un designio que, para desenvolverse y lograr propósitos ajenos y superiores a él, requería de su propia presencia física (Nieto, 1989: 32). Y así le pasó 
en Cuzco, desde donde escribió a Gerardo Diego: «he penetrado en la intimidad de esta naturaleza casi cósmica». Allí Larrea experimenta una transformación, que puede llamarse también «versión», en el sentido de gira o dar la vuelta, pues de estar vuelto sobre sí mismo, analizando su psique, ahora siente dentro de sí, y se siente, como parte intrínseca de la naturaleza, del universo (Nieto, 1989: 33). El sentido de sí mismo deja de ser individual para volverse cósmico, transformación que le producía vértigo.

Como ya se indicó, el papel del observador adquiere una importancia central tanto en Bohr y Pauli, como en Larrea. El enlace entre los instrumentos de observación (o el poeta y su lenguaje) y el sistema observado o cosmos da como resultado un conocimiento incompleto, lo cual explica el rechazo de toda expectativa realista en los poemas de Larrea. Esta indeterminación en el conocimiento es el factor que llevó a Pauli a admitir la presencia de un elemento irracional en la física, al igual que, como se está viendo, en los poemas (Pauli, 1994: 39, 36, 40). El hablante en Orbe dice que su carne y espíritu vuelven a «bañarse en el relativo del mundo», afirmando que la apetencia de lo absoluto pertenece a una concepción «científica, religiosa, social [...] vital del mundo antiguo» (Larrea, 1990: 18). La intensa introspección que Larrea (1990: 21) lleva a cabo, como constata en su diario, le produce la curiosa sensación de que el «yo no existe» pues, como el observador en la física cuántica, el poeta está inserto en la totalidad («wholeness») de la trama cósmica con los enredos o «entanglements», el término usado por Bohr (Barad, 2007: 427, notas 47 y 48) para connotar la indivisibilidad de los elementos del universo. La «intra-actuación» de los elementos en la totalidad cósmica implica una revisión de la causalidad, de la creencia en que la naturaleza posee una esencia fija y estática, ya que se trata de un devenir en constante intraactividad (Barad, 2007: 33, 422, nota 15). Para Bohr, la indeterminación que implica ese devenir se diferencia de la incertidumbre de Heisenberg, diferencia que estriba en que el principio de Heisenberg es de tipo epistemológico, al tener que ver con la incompletitud del conocimiento que poseemos sobre la realidad por no poder determinar simultáneamente la posición y el momentum, mientras que el de indeterminación tiene que ver con la falta de determinismo y es cuestión ontológica (Barad, 2007: 424-425, nota 30).

La disolución del yo se acompaña de un presentimiento de la existencia de un yo colectivo que ya empieza a desarrollarse dentro del poeta, pues, como revelan los avances en biología, el yo personal es en el fondo un yo plural constituido por «la concurrencia ordenada de tantos microorganismos» (Larrea, 1990: 53,54). Por eso nuestro autor reconoce que su poesía ha llegado a su término al admitir su identidad con la vida: todo lo perteneciente a la interioridad psíquica sentimientos, emociones, imaginación- tienen libre entrada a mi vida real», afirma (Larrea, 1990: 29,30). Muchas anotaciones en su diario insisten en la necesidad de fundir los polos contrarios de realidad e imaginación, pues su influencia mutua supone una fecundación enriquecedora para ambos (Larrea, 1990: 31). No se trata ya de indagar sobre la individualidad subjetiva, pues la identidad implica una totalidad en la que el ser humano es un participante complejo, consciente e 
inconscientemente, de esa multiplicidad en la que interviene el pasado íntegro de la humanidad y el presente de la materia cósmica.

Larrea se ha servido de su oficio poético para desempeñar el papel de ser un hombre particular que es parte de una multiplicidad (Larrea, 1990: 98). En el análisis de sus experiencias personales, Larrea (1990:120) busca correspondencias en la vida colectiva y con eventos de la humanidad. Como señala en la anotación del 26 de agosto, 1931 (Larrea, 1990: 41): «Para nosotros una existencia que no obedezca a una dualidad de desequilibrio tendiendo a equilibrarse, y por tanto condenada a muerte, es inconcebible». Situarse en la estabilización supondría un estado de encierro de la vida en su movimiento semejante a la muerte, reiterando, así, la necesidad de mantener las polaridades evitando la síntesis. Coincide así con Iyia Prigogine y su teoría del caos donde la estabilidad solo puede conducir a la muerte por calor.

Cuando afirma que en el fin último «todo se funde con el todo», Larrea está confirmando lo que la física revelaba sobre la inseparabilidad de los elementos en la trama cósmica. En esa textura se constituye la vida, de igual modo que Larrea se afirma como una amalgama de lo que es y lo que no es, siendo así «la vida misma, resumen del todo de dos maneras diferentes que al unirse se imaginan, presentando cada cual, como en un espejo, la imagen equivalente de lo que está en la otra». Por eso concluye que la vida y sus relaciones tienen la misma precisión que «la célula, [d]el átomo, [de] los electrones» ... «Y todo dentro de la complejidad aparente más incomprensible. Pero ella encuentra los medios de desatar el nudo» (Larrea, 1990: 140, 155, 160).

La identidad, como llega a entender Larrea, consiste en la correlación entre sujeto y objeto: el sujeto no puede concebir otro objeto que la vida humana y la vida humana como sujeto no puede concebir otro objeto que el ser humano. Y por encima de todo esto hay un modo de ser último que ni es sujeto ni objeto particularmente, sino que tiene que ser los dos al mismo tiempo. Esa unidad está en nosotros, pero oculta bajo las apariencias (Larrea, 1990: 216).

Lo que se concluye de toda esta exploración es que la vida es una fuerza incontenible y creativa en constante movimiento, abriéndose paso y penetrando en todos los intersticios, disfrazándose de dolor, de error, de mentira, según las necesidades creadoras. La vida actúa conforme a sus reglas y no conforme a las que el yo consciente ha querido imponerle, de igual modo que la luz y el ojo actúan de acuerdo, complementándose. El absoluto es siempre engañado pues en su misma afirmación lleva en sí el engaño: la vida es lo femenino, la invicta, la inmortal, madre, esposa e hija, concreta y abstracta, material y la inmaterial (Larrea, 1990: 225, 226, 269).

La incertidumbre en la base de la búsqueda le conduce a cuestionar la posibilidad de un asidero tanto existencial como artístico. Y al igual que Bohr, Larrea se plantea la necesidad de crear un nuevo edificio de conocimiento que se ajuste a la nueva realidad que su búsqueda le va descubriendo: realidad movible, fluida, donde todo parece mezclarse, donde los límites y demarcaciones entre las cosas, entre sujeto y objeto confluyen. En este proyecto, el cielo deja de ser la 
fuente de la providencia para tornarse ingeniero, situándose, así al mismo nivel que el de la materia inmanente. Con esta actitud de «construir», los sentimentalismos se dejan de lado pues incluso el otoño es ahora «main d'œuvre» (Larrea, 1989a:118).

Y la respuesta es la vida como totalidad arrolladora cuya clave se encuentra en la complementariedad de contrarios. Aceptar esa verdad no es tarea fácil, como revelan muchos de los poemas. El sujeto en Larrea, en busca de su autorealización, se encuentra entre lo que Hegel llama «the changeable protean», expuesto a los constantes cambios que implica la vida, y el «simple unchangeable». Mientras que el mundo proteico es familiar, finito y no siempre produce satisfacción, el infinito es fijo y estable pero fuera de alcance ( $c f$. Hannay, 1982:32). Lo que exige la vida es arriesgarse, aunque ello implique ir en contra de lo que es razonable. Larrea responde en consonancia con Ortega y Gasset quien en El tema de nuestro tiempo pedía someter la razón a la vitalidad (Pratt, 2001: 154).

En la sección de Version céleste titulada «Pure perte», el foco se sitúa en las dificultades de construir ese edificio basado en la complementariedad de opuestos que se expuso en «Ailleurs». Además de «cazador furtivo», ahora el poeta adopta la identidad de Ulises en su viajar constante en busca de esa complementariedad entre su yo interior y el exterior, entre el conocimiento y la vida, la esperanza y el desaliento. El viajero dialoga consigo mismo, jugando el doble papel de sujeto observador y objeto observado. El vértigo que implica mantener el equilibrio entre extremos opuestos le hace recaer en idealizaciones, como la de encontrar la estatua de un héroe de sol con conocimiento superior que a la vez tenga los pies a flor de agua y los ojos a flor de invierno, es decir, equilibrados (Larrea, 1989a: 166, 162).

La marca del tiempo en nuestras percepciones es uno de los factores que más directamente señala el fracaso de aferrarse a idealizaciones $\mathrm{y}$, por tanto, la necesidad de admitir la relatividad, pues el ojo capta múltiples y variables perspectivas, como sucede en el curso del tiempo. En la noche, cuando la oscuridad afecta la percepción con «ses paupières lourdes», es posible reincidir en las idealizaciones y creer poder llegar «jusqu'au jardin profond» (Larrea, 1989a:126). La seguridad de la visión asumida en las «paupières gonflées d'un air familier», se vuelve un deseo sin base. Aun así, el poeta reconoce no saber bien a qué le conducen sus distintas perspectivas, y se pregunta a sí mismo: «Monsieur de quarante ans que voyez-vous ?». Su papel es interpretar «morceaux de ciel et de nuages», lo cual no es fácil, pues esas nubes se mueven constantemente, y están «poussiéreux comme des bouteilles d'un caractère rêveur» (Larrea, 1989a: 132). El polvo sugiere que los mensajes de las nubes son difusos porque aún están envueltos en sueños de una estética ya pasada de moda

Pero el hablante insiste, pidiendo la vuelta de valores familiares y tradicionales para contrarrestar el número de víctimas del tiempo que caen especialmente en el atardecer. Lo que recibe, sin embargo, es un «horizon d'aveugle» donde «les pigeons se conduisent comme des arrière-pensées» (Larrea, 1989a: 118, 119). Los pichones no transmiten mensajes directos sino con segundas intenciones, carentes 
de transparencia. El deseo de lograr un sentido único y confiable se disuelve en alusiones, probabilidades y conjeturas, confirmando la imposibilidad cuántica de lograr un conocimiento completo (Larrea, 1989a: 100). Muy a menudo, el horizonte está lleno «d'alarmes éphémères» o esplendores vanos que seducen con imágenes de «fleuve des fleurs» transcurriendo realmente «par les sables des sables». Pero algunas veces en ese trayecto el horizonte «ouvre sa main et quelque beauté s'envole», o bien, «chaque jour nous sert une aile d'horizon posible», ala para continuar en el vuelo hacia ese «ailleurs». Y estos signos esperanzadores se producen «dans la vaisselle que casse votre rire» (Larrea, 1989a: 126, 132,120), es decir, cuando el tú se ríe de los valores domésticos de la burguesía rompiendo la vajilla, algo tan propio de esa clase social, rompiendo así con sus valores establecidos.

Por eso afirma que la búsqueda se sustenta en «les rapports existant entre mes yeux et les bourgeons de femme» (Larrea, 1989a:122). «Bourgeons» apunta al despertar de la sexualidad, pero también a la naturaleza y su secreto de vida. La visión (ojos) del poeta se orienta al ir hallando «bourgeons» en los que va percibiendo vislumbres del Tú o Ella, encarnación de la creatividad y la vida como si, según sucede con los experimentos cuánticos, cada caso de observación supusiera un estado epistemológico nuevo y diferente. Esos «rapports» señalan el reconocimiento por parte del poeta de la necesidad de establecer enlaces complementarios entre sus ojos o percepción y esos brotes de mujer, dos ángulos que deben yuxtaponerse y hacerse complementarios.

Junto a las dificultades en ver y percibir, el sujeto experimenta la disgregación en su propio ser, acosado por todas partes por espadas que lo cortan en pedazos («Il y a partout des épées qui me coupent»), teniendo que andar sobre cavernas «craquantes comme des crânes»-el posible final de todas sus cavilaciones mentales- y ni los pájaros que duermen en sus ojos pertenecen a esos ojos (Larrea, 1989a:162) pues los ojos, sede de la percepción, carentes del vuelo creativo, se ven reducidos a un mirar limitado. El hablante se identifica con los vencidos cuyas ventanas están empavesadas por el hollín oscureciendo toda visibilidad y «les contingences se pressent à la porte comme des mendiants». Sus sueños le abandonan «sans un geste de cambrioleurs surpris» (Larrea, 1989a: 200, 202), analogía que señala la gravedad de perder los sueños pues ni siquiera hay un intento de ocultar el propio abandono, y sus lágrimas en forma de cruz, lo señalan como víctima expiatoria. $\mathrm{Y}$ aunque trata de continuar en su marcha como si nada hubiera pasado, «l'horizon fait figure d'une confiance mal placée» (Larrea, 1989a: 202). A su vez el Tú, el espacio donde debería darse la complementariedad tiene una lengua ahuecada y triste, incapaz por ello de disipar la niebla, con ojos vacíos que no pueden concebir un conocimiento nuevo, y «elle est inachevée comme une église» (Larrea, 1989:216). La analogía de una iglesia inacabada sugiere el incumplimiento de Ella y sus promesas. El hablante se siente «dans l'invincible mer de fouets qui m'inonde», otro ejemplo de percibirse como víctima expiatoria. De las gentes solo recibe cóleras y reducido a la soledad, el poeta percibe el universo inundado «de rencontres de cloisons et de pertes». El Tú presenta un amor de are- 
na, cobijando niños (esperanzas) adormilados. Los dedos con que proceder en la escritura están secos, con solo vestigios de lluvia (Larrea, 1989a: 224, 232, 238,240). La única manera de prolongar su vida es gracias a la golondrina tan becqueriana que vuelve cada primavera, permitiéndole seguir aferrándose a sueños románticos.

La realidad del Tú/Poesía/Ella, donde debería ubicarse la complementariedad, se expresa en un subjuntivo o condicional de probabilidad, indicando lo que pudiera haber sido, pero no es ni llegó a ser. Es un Tú que depende de una hermosura volandera, perdida en selvas de error, poco estable y que traiciona su ardor al expresarse en hojas o escritura procedentes de un pecho débil sometido a los extremos de luz y abismo (Larrea, 1989a: 165).

El mundo entorno a veces se articula como un «nosotros» donde todos nos hallamos incluidos con rostros demacrados y cuerpos fragmentados, pues estamos «malades dans la haine» o, lo que es igual, carentes del amor que proporcionaría los enlaces necesarios. Nuestros gestos descarnados son signos de edificios personales «laissant tomber des murs le long de notre corps», las gentes expresan cóleras y violencia, y tienen olvidos a los que el poeta debe sacrificar sus deseos «d'atteindre le lendemain» (Larrea, 1989a: 166, 194, 192). Todo entorno adopta un giro doliente, carente de armonía, pues el universo ya no es una flauta y el camino del poeta pierde contornos al blanquearse en las arenas del tiempo (Larrea, 1989: 202). El poeta evoca el ubi sunt manriqueño, pero el mundo se ha convertido en «un miroir inégal» de reflejos erróneos, un tejido «de toits vitreux», un desierto (Larrea, 1989a: 204, 222). Estas imágenes especulares y de reflejos falsos muestran el fracaso de la complementariedad entre opuestos. «Nosotros» es un grupo sin corazón, que «change de costumes aux couleurs» sin ofrecer ninguna certeza (Larrea, 1989a: 168, 170). El individuo se diluye girando como un molino en todas las direcciones. El Tú/Ella es una «sœur inachevée», pues la yuxtaposición con su contrario no se ha realizado (Larrea, 1989a: 190, 186).

En la última sección del libro, con igual título al de toda la colección, el poeta ha llegado a la edad de 40 años y reconoce que el azar y los peligros no se pueden controlar (Larrea, 1989a: 244). El espejo donde se reflejaba la imagen propia se hace añicos («Éclats de glace», 1989a: 252), destruyendo toda esperanza de complementariedad entre imágenes contrarias. Aunque el camino se abre a una multiplicidad de opciones, todas permitidas y todas hermosas, se trata también de un riesgo por el temor a caer en la locura, el delirio o la creencia en esplendores que solo proporcionan una visión efímera. Lo que se busca es «la voie des éclairs impérissables» (Larrea, 1989a: 256), otro intento de idealización, donde las epifanías no serían efímeras. Aunque el poeta/Ulises, revelando la astucia del nombre que ha adoptado reconoce tener dos ojos, uno encantador y otro perturbador, de nada le sirve esa doble capacidad perceptiva para llevar a cabo una yuxtaposición de contrarios; lo que consigue es un eclipse «de terre / bien sûr à s'y méprendre» (Larrea, 1989a: 268).

La complementariedad fracasada en estos versos se debe, según indica el poeta, a que la vida, como «torche / inapprivoisée», ha desvelado su enigma pre- 
sentándose como una fuerza inagotable e incontrolable. La vida es una «aventurière» que se ha despojado de los velos, máscaras y supersticiones procedentes de los grandes discursos religiosos, filosóficos, científicos y culturales de la tradición occidental. En su desnudez, la Vida supone un reto a todo intento de equilibrio. Por eso la llama «Angelique éclatante», de lo cual resulta una «anxiété des signes» (Larrea, 1989: 244, 248). El azar y el porvenir sellan sus formas inciertas en las sienes de la vida constituyendo su esencia. La vida es «d'elle-même entourée d'elle même» pues no hay nada más allá: «L'ambre nu de la vie n'offre plus de résistance» (Larrea, 1989a: 244, 248, 250, 252, 254). Ambos, Bohr y Larrea coinciden en reconocer la verdad irreducible de la vida, fuerza que, por su carácter imparable, resulta admirable, incomprensible e inabarcable.

Como «fille-phare», la vida está fuera de sí, «éperdue», como se expresa en el «moutonnement des races» y en la «pluralité de mères». El poeta parece incapaz de contener el poder arrollador de la vida. Por eso ha dejado atrás el «sceptre» y la «pourpre», distintivos de sistemas jerárquicos, para que la vida tome la iniciativa de seguir el camino de los espejos con sus múltiples reflejos, es decir, de admitir el multiperspectivismo con todos sus riesgos: «elle prend toute entière le chemin du miroir» (Larrea, 1989a: 286, 288). Volviendo a la imagen especular, la manera de lograr la complementariedad va a estar en las impredecibles manos de la vida.

Esta resolución implica el rechazo de modas y corrientes poéticas distanciadas de la vida, como el modernismo. Por eso el cisne está en su ataúd de orgullo y la plaza del honor bosteza. Ahora lo que predomina y es fuente de gozo es hallarse en «pêle-mêle de leur promiscuité», es decir, ser parte intrínseca de la vida asumiendo todos sus enredos. El Tú, «ô toujours Contournée», refleja la realidad de los enredos y la importancia del contexto. Ella es ahora «la Dernière Page», pues no hay nada más allá de Ella/vida. Y bajo la parra, referencia a la planta de donde procede la vendimia del conocimiento a partir de una entrega dionisíaca a expensas de la razón, vivir «devient la grappe imposible d'atteindre». La inagotable vida es una «hémorragie» difícil, si no imposible, de controlar o de entender su dirección. Es una fuerza que se resiste a la conceptualización. Ella/vida es «délayée insaisissable» (Larrea, 1989a: 302, 310, 312, 246).

El reconocimiento de lo irreducible de la vida no soluciona el papel que debe jugar el plano mental, y aceptar la vida implica aceptar la realidad del azar. La certidumbre de los grandes discursos, representada en el sol, se ha reemplazado por el deseo cuyo color verde sustituye al dorado tiñendo el sol con el color de la Vida. El poeta busca hallar un soporte ante la incertidumbre, incluso los árboles buscan la supervivencia «dans l'éloquence du nombre», tratando de controlar la fuerza de la Vida con el rigor matemático. Pero la Naturaleza se vuelve «indu» (Larrea, 1989a: 284, 298, 258) o inapropiada dejando el proceso en suspenso, sin saber cómo o por qué optar. Hay serios intentos de establecer lazos entre los polos opuestos con brazos imaginarios que se buscan y se alargan desde una a otra orilla de la llama, «des bras se cherchent des bras s'allongent / imaginaires / d'une rive a`une autre rive de la flamme». Pero la vida es «cette joie si vive qui naît de tout 
confondre», que supera todo intento de jerarquía en una mezcolanza donde reside el azar o «des coups de dés» (Larrea, 1989a: 246, 280, 282).

El poeta se experimenta como dividido, y la dualidad parece triunfar como un «tragique contraste de l'aube et du granit», dos elementos muy distintos, el uno de apertura y evanescencia, el otro de dureza y rigidez. La dualidad se presenta como una boca cuyas mandíbulas trituran «une clarté vivante» (Larrea, 1989a: 296, 300, 316). Al destruir la trasparencia lo que queda son ojos cerrados y fijos en la certeza de que no es posible alcanzar un conocimiento completo y certero. El poeta se refugia en la choza de su limitado saber, donde el oro y el éxtasis ven sus idealizaciones esfumarse en «le ciel attaché à une colonne fuyante de fumée». Por eso el poeta se ve en la necesidad de urdir «tissus d'urgence». Se va «de vide en vide», y cuando se vuelve a buscar soporte en las madres (el pedernal madre u origen), algunas están hechas pero otras madres están en ruinas y lo que pueden hacer es esperar aquí y allí «comme des trapes»(Larrea, 1989a: 320, 258, 266) pues lo que ofrecen de seguridad y origen tampoco está claro.

Cuando el poeta dice que la poesía no es pan reitera lo que ya dijo en «Carta abierta a J. Lipchitz» de que el arte creativo no es cuestión de pan sino de «Palabra» creativa, formulación del Espíritu, para y por el Espíritu (Larrea, 1984: 187). El logro de esa palabra debería llevar a una nueva dimensión o estado vital: extraindividual, suprasocial, transconsciente, espiritual:

Porque así como la supuesta disolución matemática por los desiertos de lo abstracto está conduciendo al beneficio de la energía intraatómica, así la abstracción poética en la entraña de sus refinados caleidoscopios hace posible el advenimiento a conciencia y la implantación de las vivencias esenciales en la heredad del Hombre (Larrea, 1984: 189).

La cita apela a la abstracción en los planos científico y poético, supuestamente como un medio de mantenerse a flote ante la avalancha de la vida. Pero, la interrogación al final, «¿Paraíso?», pone en entredicho la propuesta de recurrir al plano de la abstracción.

\section{Conclusiones}

Larrea y Bohr coinciden en señalar una serie de áreas y puntos donde se da cita la correspondencia entre las artes y las ciencias. Su entendimiento de la transdisciplinariedad, de que los campos del saber son una totalidad, es fundamental tanto para el desarrollo del principio de la complementariedad como para el entendimiento de lo que es la vida. Para ambos la clave de la vida se halla en el principio de la complementariedad como lucha o encuentro entre dos polos opuestos en cuya yuxtaposición se asienta el movimiento vital. Ambos reconocen que en este constante movimiento domina lo que Heisenberg representó en su principio de incertidumbre -de que nunca podemos lograr un conocimiento total-, así como el de la indeterminación de Bohr que no solo apela al conocimiento, sino también a la ontología. Reconocen ambos el papel fundamental del observador y su inserción con el objeto observado, la indivisibilidad de los elementos que cons- 
tituyen la trama cósmica y que responde a su complejidad, el desplazamiento de la causalidad y la existencia de ciertos modelos o patrones que apuntan a un espíritu universal o de la época ( $c f$. Caro y Murphy, 2002: 3).

El lenguaje de Larrea responde a lo que se entiende como estética cuántica porque su factor distintivo es ser una producción y no una representación. Y es así porque el texto no se refiere a una realidad objetiva que está ahí fuera, sino inventada. Se relaciona, entonces, con el entendimiento que Bohr tiene del lenguaje común como el medio necesario para las descripciones cuánticas, repetido en muchos de sus escritos, pues no se trata de representar la realidad, sino los elementos no accesibles de ella (Bohr, 1963: 10, 11, 59) ${ }^{8}$. Ambos, entonces, configuran un nuevo tipo de objetividad. Como el sujeto observador está enredado con el objeto observado lo que resulta es materia mental. El dinamismo en el mundo cuántico no puede interpretarse de manera dualista sino como un todo donde cada polo solo se entiende en relación con su opuesto. Esto significa que la «identidad existe en la diferencia» ya que un aspecto no se da sin trazar al otro. Significa, además, que el acercamiento debe ser holista (Caro y Murphy, 2002: 38, 79).

Artistas como Larrea, y físicos, como Bohr, se confrontan con un mundo en movimiento constante donde el tiempo no es una medida de secuencias sino un campo dinámico de relaciones. En este dinamismo se producen las yuxtaposiciones y superposiciones, haciendo que los contornos entre las cosas se diluyan. Se trata de un mundo donde espaciotiempo está dinamizado y no hay puntos focales discernibles. El pasado no ha desaparecido ni el futuro está por venir pues todo está aquí y ahora. En esta «copresencia» de eventos, no hay espacio para la identidad total de cualquiera de ellos (Caro \& Murphy, 2002: 81, 83). Hay que recurrir, entonces, a un lenguaje en flujo, y al haber una superposición de fenómenos, la perspectiva se confunde. Como ya se ha visto, Larrea se refiere a este fenómeno como la fuerza arrolladora e incontrolable de la vida.

Por eso Larrea creía que « Por los contrarios se encarama uno, y luego sacrificar el deseo de encaramarse». Y es mediante la yuxtaposición de los contrarios que «encaramarse», como subirse a un lugar alto, se hace posible. Tras haberlo logrado, la cita apela a sacrificar ese mismo deseo que llevó a la yuxtaposición, evitando una síntesis que sería sinónimo de estatismo. Y así lo confirma el poema «Contradicción» donde Larrea reconoce la necesidad de contradecirse uno mismo, pues, de no hacerlo, la persona se volvería una estatua de mármol cerebral. Sería un huir del tiempo y olvidarse de la realidad (Bary,1984: 172). Negarse debe implicar afirmarse, pero sin optar ni por lo uno ni por lo otro, sino por ambas cosas a un mismo tiempo para llegar a un estado superior donde sea posible ver ambas desde abajo.

\footnotetext{
${ }^{8}$ La insistencia en el uso del lenguaje común en la descripción de las observaciones se cumple, como señala Bohr, en los detalles específicos sobre el experimento y los aparatos usados. Incluso en las matemáticas, añade el físico, se recurre a un uso general del lenguaje, con el suplemento de ciertos instrumentos que resultarían torpes en la descripción ordinaria (Bohr, 1963: 60).
} 
En su ensayo sobre la transdisciplinariedad de Nicolescu, Francis-Norbert et al. (2012: en línea) sitúan ese «estado» en un nivel ternario o interfaz entre sujeto y objeto:

and the object not having to do properly neither with the subject nor with the object, and not even with an eventual divine origin or climax of the syntheses or synesthesia of the two. It solely offers the possibility for a dialogue between antagonisms, and does not replace them, nor does it synthesize them. It behaves as a catalyst or substance that accelerates or decelerates a chemical reaction. The Hidden Third assures the connection between different levels of reality through a phenomenon of paradox, of coincidentia oppositorum, of being $\mathrm{A}$ and non- $\mathrm{A}$ at the same time.

Y lograr ese espacio entre junturas es lo que Larrea se propuso al «entrar en poesía», pulverizando, mediante el idioma francés, su sistema de creencias y su lenguaje, renunciando así a su herencia cultural en sus aspectos más exteriores y superficiales y salirse «de los límites tradicionales de la conciencia dualista de Occidente» (Bary, 1976: 22-23).

La reacción de Larrea, al constatar la incertidumbre en la base de su subjetividad, posibilita imaginar la de los físicos en la cuántica al descubrir, en contradicción a todo lo que se creía, que la materia consiste en una miríada de partículas en movimiento, eludiendo toda base en un último nivel de la realidad, cuyas interacciones no responden a los principios de causalidad y localidad y cuyo indeterminismo contradice las certezas de la física clásica. Y como todo está constituido por átomos, todo lo que se debe de entender como vivo tiene que incorporar o tomar en cuenta esos constantes temblores y meneos de los átomos en la base de la materia y de la identidad ${ }^{9}$.

La física cuántica, según Heisenberg, uno de sus portavoces, refleja el Zeistgeist o espíritu de la época, equivalente al Espíritu universal y colectivo del que habla Larrea, como noción donde se acumulan las memorias, creencias, mitos de la humanidad sobre una naturaleza eterna. A los artistas es a quienes les toca articular ese Espíritu universal, según señala Heisenberg (1958: 109), y Larrea lo lleva a cabo mediante su personal estilo en Versión celeste, dejándose conducir por los medios que le ofrece el idioma francés, arriesgándose al azar de las pala-

${ }^{9}$ En una anotación en Orbe, Larrea (1990: 12-13) escribe que estando en el hipódromo tuvo la experiencia de una «dislocación de la idea de tiempo» constatando que, «sueño y realidad, consciente e inconsciente, idea de yo y de no yo, idea de tiempo y eternidad se compenetraban íntimamente» siendo inútil «intentar discernir donde empezaba una y terminaba otra». El resultado fue la necesidad de «modificar en principio la idea de mí mismo». En otro lugar, Larrea (1990: 17) registra la experiencia del «enrarecimiento del yo» pues de haberse sentido como algo sólido, cristalizado, «invariable de pasados tiempos quedó reducida[o] a un estado gaseoso a merced de los más débiles agentes. No existía puesto alguno donde apoyarse». Estas reflexiones sobre su propia subjetividad reflejan los avances en la física sobre el átomo y la materia que, de presencia sólida estaba revelando la misma porosidad y estado gaseoso de que habla Larrea en su subjetividad. 
bras en cuyo fluido radioactivo cada cosa puede ser y es otra cosa (1987: XII). Pero los escritos que se han venido citando -Orbe, «Presupuesto vital», «Carta abierta a Liptchitz», Version céleste- expresan sin reservas la total dedicación del autor al principio de complementariedad, junto con la angustia y desaliento ante la dificultad de mantenerlo. Lo que queda, como hizo Bohr, es aceptar lo irreducible de la vida pues, en última instancia, se trata de una cuestión de vida.

\section{REFERENCIAS BIBLIOGRÁFICAS}

AgAmBEn, Giorgio (2009): The Signature of All Things. On Method. Traducción de Luca D'Isanto y Kevin Attell. Nueva York, Zone Books.

BARAD, Karen (2007): Meeting the Universe Halfway. Quantum Physics and the Entanglement of Matter and Meaning. Durham \& Londres, Duke University Press.

BARY, David (1976): Larrea: Poesía y transfiguración. Barcelona, Planeta.

BARY, David (1984): «Sobre la poética de Juan Larrea», in Nuevos estudios sobre Huidobro y Larrea. Valencia, Pre-Textos, 107-123.

BARY, David (1987): «Introduction», in A Tooth for a Tooth. Selected Poems of Juan Larrea (1925-1932). Lanham, University Press of America, VII-XIII.

BoHM, David (1985): «On Bohr's Views Concerning the Quantum Theory», in A.P. French A.P. y P.J. Kennedy (eds.), Niels Bohr. A Centenary Volume. Cambridge (Mass.), Harvard University Press, 153-159.

BoHR, Niels (1958): Atomic Physics and Human Knowledge. New York, John Wiley \& Sons, Inc.

BoHR, Niels (1963): Essays 1958-1962 on Atomic Physics and Human Knowledge. Nueva York, Londres, Interscience Publishers.

CARO, Manuel J. \& John W. MURPHY [eds.] (2002): The World of Quantum Culture. Wesport (Conn.), Praeger.

CIFRE-WIBROW, Patricia (1984): «Los estudios interdisciplinares sobre Schnitzler y Freud. ¿Atrapados en la trampa de la analogía?», in David Bary, Nuevos estudios sobre Huidobro y Larrea. Valencia, Pre-Textos, 265-309.

CORDERO DE CIRIA, Enrique \& Juan Manuel DíAZ DE GuEREÑU [eds.] (1986): Juan Larrea: Cartas a Gerardo Diego 1916-1980. San Sebastián, Facultad de Filosofía y Letras de la Universidad de Deusto.

DAVIES, Paul (1982): Other World. Space, Superspace and the Quantum Universe. Nueva York, Simon \& Schuster.

FRANCISC-NORBERT, Ormeny y Theodora-Eva STÂNCEL (2012): «Transdisciplinary Approach of Imagination and Angels - The Transcultural Hidden Third: From Andrei Plesu to Basarab Nicolescu». Studia Universitatis Babes-Bolyai. Studia Europaea, 57:1, 129-159. URL: https://web.a.ebscohost.com/abstract?direct=true\&profile $=$ ehost $\&$ scope $=$ site $\&$ authtype $=$ crawler $\&$ jrnl $=12248746 \&$ asa $=Y \& A N=745$ 59493\&h=Pwi\%2fTs\%2b4T9QWdQ9. 
GalA, Candelas (2016): Sinergias. Poesía, física y pintura en la España del siglo XX. Traducción de Isabel Palomo. Barcelona, Anthropos.

GAMONEDA, Amelia (2015): «Lugar común», in Amelia Gamoneda (ed.), Espectro de la analogía. Literatura \& Ciencia. Madrid, Abada Editores, 5-15.

GAMONEDA, Amelia (2015): «Resistencia y flexibilidad de la analogía. Modelos científicos, cognición y metáfora», in Amelia Gamoneda (ed.), Espectro de la analogía. Literatura \& Ciencia. Madrid, Abada Editores, 93-175.

GONZÁLEZ FERNÁNDEZ, Francisco (2015): «El diccionario romántico de Poincaré», in Amelia Gamoneda (ed.), Espectro de la analogía. Literatura \& Ciencia. Madrid, Abada Editores, 17-91.

HANNAY, Alastair (1982): Kierkegaard. Londres, Boston, Melbourne y Henley, Routledge \& Kegan Paul.

HAYles, N. Katherine (1984): The Cosmic Web. Scientific Field Models \& Literary Strategies in the $20^{\text {th }}$ Century. Ithaca y Londres, Cornell University Press.

HEISENBERG, Werner (1985): «Reminiscences from 1926 and 1927», in A.P. French \& P. J. Kennedy (eds.), Niels Bohr. A Centenary Volume. Cambridge (Mass.), Harvard University Press, 163-171.

HEISENBERG, Werner (1969): La imagen de la naturaleza en la física actual. Barcelona, Seix y Barral.

HEISENBERG, Werner (1958): Physics and Philosophy. The Revolution in Modern Science. Edición de Ruth Nanda Anshen. Nueva York, Harper \& Brothers Publishers.

HOFSTADTER, Douglas \& Emmanuel Sander (2013): Surfaces and Essences. Analogy as the Fuel and Fire on Thinking. Nueva York, Basic Books.

HONNER, John (1987): The Description of Nature. Niels Bohr and the Philosophy of Quantum Physics. Oxford, Clarendon Press.

ILIE, Paul (1970): «The Surrealist Metaphor in Juan Larrea». Symposium, 24, 330-339.

JONES, R. V. (1985): «Complementarity as a Way of Life», in A.P. French \& P. J. Kennedy (eds.), Niels Bohr. A Centenary Volume. Cambridge (Mass.), Harvard University Press, 320-324.

Kothari, D. S. (1985): «The Complementarity Principle and Eastern Philosophy», in A.P. French \& P. J. Kennedy (eds.), Niels Bohr. A Centenary Volume. Cambridge (Mass.), Harvard University Press, 325-331.

LARREA, Juan (1954): «An Open Letter to Jacques Lipchitz». College Art Journal, 13:4, 251-288.

LARREA, Juan (1984): «Carta abierta a Jacques Lipchitz». Poesía: revista ilustrada de información poética, 20-21, 167-190.

LARREA, Juan (1987): A Tooth for a Tooth. Selected Poems of Juan Larrea (1925-1932). Traducción e Introducción de David Bary. Lanham, University Press of America.

LARREA, Juan (1989a): Versión celeste. Ed. Miguel Nieto. Madrid, Cátedra.

LARREA, Juan (1989b): «Presupuesto vital», in Miguel Nieto (ed.), Versión celeste. Madrid, Cátedra, 350-355.

LARREA, Juan (1990): Orbe. Edición de Pere Gimferrer. Barcelona, Seix y Barral. 
MACKINNON, Edward (1985): «Bohr on the Foundations of Quantum Theory», in A. P. French \& P.J. Kennedy (eds.), Niels Bohr. A Centenary Volume. Cambridge (Mass.), Harvard University Press, 101-120.

NiCOLESCU, Basarab (2013): Teoremas poéticos. Traducción de Clara Janés. Madrid, Salto de página.

NIETO, Miguel (1989): «Introducción», in Juan Larrea, Versión celeste. Madrid, Cátedra, 11-57.

PAULI, Wolfgang (1994): Writings on Physics and Philosophy. Edición de Charles P. Enz \& Karl von Meyenn. Traducción de Robert Schlapp. Berlin, Springer-Verlag.

Petersen, Aage (1985): «The Philosophy of Niels Bohr», in A.P. French \& P. J. Kennedy (eds.), Niels Bohr. A Centenary Volume. Cambridge (Mass.), Harvard University Press, 299-310.

PratT, Dale J. (2001): Signs of Science. Literature, Science, and Spanish Modernity since 1868. West Lafayette (Ind.), Purdue University Press.

SMith, Alan E. (1995): «“Un color le llamaba Juan”. La elegía y el mito». Ínsula, 586:12, 17-18.

WHEELER, John A. (1985): «Physics in Copenhagen in 1934 and 1935», in A.P. French \& P. J. Kennedy, Niels Bohr. A Centenary Volume. Cambridge (Mass.), Harvard University Press, 221-226. 